\title{
A Study on Food Self-Sufficiency at Household Level in Nepal
}

\author{
Keshav Lall Maharjan (IDEC, Hiroshima University) \\ Arun K. C. (IDEC, Hiroshima University)
}

\section{Introduction}

Nepal is an agricultural country and is dependent on it for her food needs, employment of the people and the economy as a whole. Recent agricultural development in Nepal has been slow and its contribution to the gross domestic products (GDP) has declined to less than $40 \%$ in 2002/ 03 (MOAC 2003). However, more than 65\% of labor force is still directly dependent on it for employment. Weak agricultural growth, primarily subsistence in nature, is the main cause of low growth in the nonagricultural sectors, consequently limiting the possibilities for overall economic growth (APROSC and JMA 1995). This would make the people more dependent on agriculture to meet their daily needs, especially the food.

On the other hand, Nepal has experienced rather high population growth in recent decades. This coincided with limitation in the expansion of farmland has caused the decrease in per capita availability of land and the landholding area (own and operated land) per household. This along with the limited economic growth has grossly contributed in the increase of poverty in the country. In addition, the weak agricultural growth, characterized by stagnation in production of major cereal crops, has made more of the households to be vulnerable in meeting their selffood needs. Most of the households in the hills and mountains annually experience food deficit from their own production. About $85 \%$ of the hills and $82 \%$ of all mountain districts are food deficit districts (CBS 2003a). The small farmers with lesser landholdings in these regions are the more vulnerable ones in meeting their food needs.

Considering these points, this paper will study the state of food self-sufficiency at the household level based on self-food production. In doing so, population growth rate, incidence of poverty, cereal crop production, distribution of land and household income will be examined for the discussion. It will also discuss the alternative strategies undertaken by the self-food deficit households to meet their food needs.

\section{Population and poverty}

National population size and growth rate has direct impact on the aggregate food availability per capita in average terms and put greater pressure on natural resources; land and forest. Over the past nine decade, Nepal's population increased by almost 4.10 times from 5.6 million in 1911 to 23.1 million in 2001. Before 1930, the population growth rate was negative $(-0.07 \%$ per year $)$, but the population started to grow thereafter (CBS 2003b). In the latest census of 2001, Nepal's annual population growth rate reached $2.25 \%$. This high population growth rate has not only increased annual food requirement by more than $2.25 \%$ but also has exerted pressure on an already intensively used land resource base. In Nepal, particularly in hills and mountains, agriculture is being practiced in environmentally fragile slopes. Increasing population pressure on cultivated land, grazing land and forestland to fulfill growing food demand has lead to rapid natural resource degradation (Adhikari and Bohle 1997 \& Ojha 1999). This has serious impact on yield and production of food crops (cereals consisting of rice, wheat, maize, millet and barley) as well as meeting the food needs of the people.

One of the major elements in the definition of poverty is inadequacy of food. Poverty and food insecurity are closely interrelated and the poor in Nepal constitute the largest food insecure group. With $85 \%$ of the total population living in 
rural areas, poverty is much more prevalent and severe in rural areas. Many of the rural poor are smallholders with landholdings less than 0.5ha (defined by National Planning Commission) and or landless people seeking to sell their labor in various activities to secure their food needs. They depend on agriculture or agro based nonfarm jobs for their earnings, either as producers, tenants or hired workers. The rural poor generally produce less grains than what they need for consumption, sometimes covering just three months of annual household needs (FAO 2004). Poverty is increasing in Nepal at an annual rate of more than $3 \%$ with the number of absolute poor almost doubled in the past 24 years between 1977 and 2001. Nepal Human Development Report indicates that poverty estimated by National Planning Commission was $36.2 \%$ in 1977, which according to Multipurpose Household Budget Survey grew to $42.5 \%$ in 1985 and according to National Living Standard Survey to $45.0 \%$ in 1996 (NESAC 1998). These estimates also indicate that poverty is more rampant, deeper and sever in rural areas than urban areas. As of 2001, about 10 million of people, comprising $42 \%$ of the total population, $44 \%$ in rural area and $23 \%$ in urban area, are regarded as poor (CBS 2003b). The rural poor are characterized by a high dependence on the agriculture that is characterized by low yield rate, inaccessibility to extension services and markets and small size of landholding. These poor people almost always have to resort to native coping strategies such as eating coarse grains, edible wild roots and plants, and doing away with meals in extreme cases.

\section{Cereal crop production}

The factor that influences the most in the domestic food availability (per capita) is the growth rate of food production. Total production of the country's food commodities serves as a good indicator of the overall food security position of the country and has direct impact on household level food self-sufficiency as well as food security in an agrarian economy like Nepal.

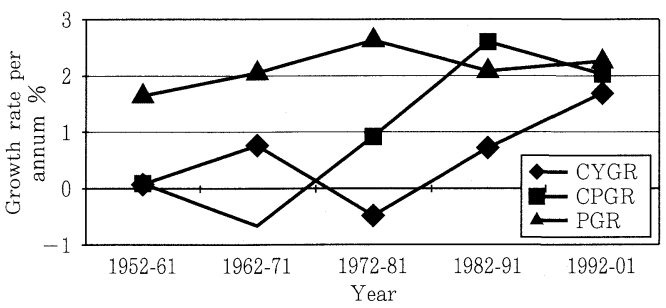

Fig. 1 Growth rates of yield and production of crops, and population in Nepal, 1952 to 2001

Source: Enumerated from FAOSTAT 2004 \& MOAC 2003. Note: CYGR $=$ crop yield growth rate, $\mathrm{CPGR}=$ crop production growth rate, $\mathrm{PGR}=$ population growth rate.

In Nepal, the population's diet is based predominantly on cereals that provide more than $75 \%$ of total energy requirement (FAO 1998). Forty years production trends of cereal crops from 1961 to 2001 at the national level indicate that growth rate of yield and production is very low as compared to population growth (Fig. 1). Only during recent decades these growth rates have become similar, partly due to decrease in population growth rate and partly due to increase in crop production growth rate, achieved due to the expansion of cultivated area rather than the increase in crop yield growth rate.

Accordingly, the per capita food production is decreasing since 1950 s from $271 \mathrm{~kg} /$ person/year during the decade of 1950 s to $206 \mathrm{~kg} /$ person/year during the decade of 1990s (FAOSTAT 2004 and MOAC 2003). Since then Nepal started to import food grains to feed her population, although tarai still produces food more than its needs.

\section{Land distribution, household income and pov- erty}

Distribution of cultivated land is important factor to fulfill household food demand in agrarian economies. In Nepal, only $20 \%$ of the geographical area is cultivated and the potential for expansion of this area is extremely limited given the topography, the climatic conditions and the moderate soil fertility. According to the Human Development Report 1998, the bottom $40 \%$ of the population own only $9 \%$ of the arable land whereas the top 6\% own around 33\%. Landholdings of about $47 \%$ of the households are less 
than $0.5 \mathrm{ha}$ in size, and $75 \%$, below one hectare (CBS 2003b). These 75\% households occupied only $39 \%$ of the total land where as $25 \%$ of the households having land more than one hectare occupied $61 \%$ of the total land. In addition to such an unequal land distribution, landholdings are small and getting further smaller, with average size per household being decreased from 1.11ha in $1961 / 62$ to 0.8ha in 2001/02 (CBS 2003a) and the share of households with landholdings less than 0.5ha increasing from 1991/92 to 2001/02 (Fig. 2). One can easily guess from these trends that many smallholders are being marginalized and transformed into hired laborers who need to rely on scarce wage employment and seasonal migration for securing their food needs.

Being an agricultural country, there is a strong relationship between the size of landholding and household income in Nepal. According to NRB 1988, the average household income of large landholders was nearly 3 times higher than that of the marginal landholders. Similarly, the income of the large landholders was more than $50 \%$ higher than that of the medium landholders, and nearly double that of small landholders. The average household income of the landless households in the rural areas was just one-third that of the large landholders (Fig. 3). This figure also shows that the incomes of the large and medium landholders in tarai are much higher and the income gap between them and the smallholders (small and marginal landholders, and landless households) are bigger than the other geographical regions and Nepal as a

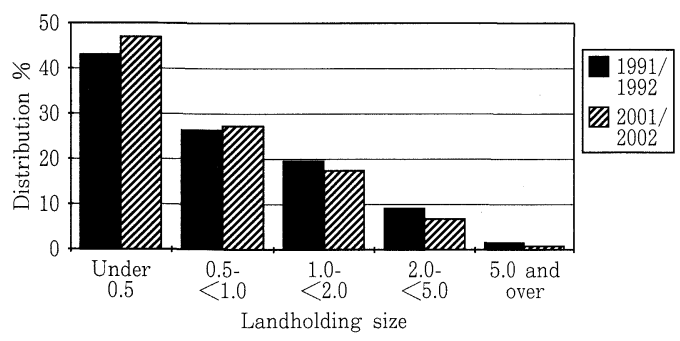

Fig. 2 Distribution of households by landholding size in Nepal, 1991/92 and 2001/02

Source: CBS 1993 \& 2003a.

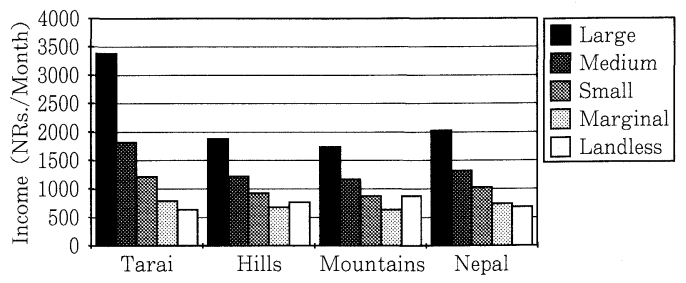

Fig. 3 Household income according to landholding size and geographical region in Nepal

Source: NRB 1988. Note: Landholding size of, Large household = $>5.4$ ha in Tarai and 1.04ha in the Hills and Mountains; Medium household $=2.73 \mathrm{ha}$ to $5.4 \mathrm{ha}$ in Tarai and 0.52 to $1.04 \mathrm{ha}$ in the Hills and Mountains; Small household $=1.03$ to $2.73 \mathrm{ha}$ in Tarai and 0.21 to $0.52 \mathrm{ha}$ in the Hills and Mountains; and Marginal household $=$ up to $1.02 \mathrm{ha}$ in Tarai and up to $0.21 \mathrm{ha}$ in the Hills and Mountains. $1 \mathrm{NR}$ (Nepali rupee) is equivalent to 1.6 Japanese yen.

whole. This indicates that there is a direct relation between household income and size of landholding in the rural areas of Nepal.

Incidence of poverty and landholding is also related in Nepal. According to Sharma and Chhetry 1996, the sample survey report of Central Bank of Nepal indicates that poverty is very much concentrated among the smallholders and the households with landholdings of 0.5-2ha (Fig. 4). This figure also shows that the percentage of the poverty incidences are higher in hills and mountains than tarai and more than 70\% the smallholders and more than 50\% of the households with 0.5 -2ha of land are poor in the regions of hills and mountains.

\section{Land distribution and food self-sufficiency}

The prevailing low productivity situation prevented required volume of production of cereals to feed the population, showing a deficit of food requirement in the country. In terms of selfsufficiency of agricultural produce to feed the households, agriculture census of 2001/02 shows that almost $60 \%$ of the households are selfinsufficient to feed themselves from their own produce (CBS 2003a). Regionally, more of the households in the hills are less self-sufficient as compared to the mountains and the tarai. This food self-sufficiency is directly related to the distribution of the land resource. Fig. 5 indicates the relationship between landholdings and food self-insufficiency in regional and the national 


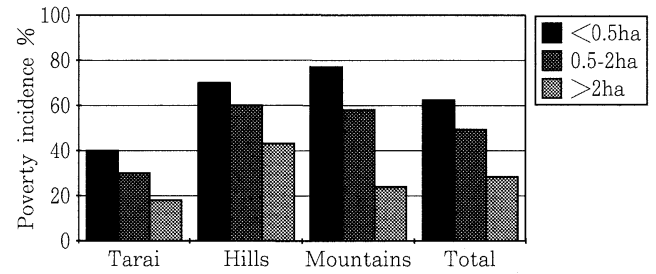

Fig. 4 Incidence of poverty according to landholding size and geographical region in Nepal

Source: Sharma and Chhetry 1996.

context. Households with more than 2 ha of landholdings reported the lowest proportion (2\%) of self-insufficient to feed the household members form their own produce. But the number of households with such an amount of landholding is not many in the total number of households. Moreover, almost all of them (90\%) felt the problem of food self-insufficiency only for six months as the longest period. Similar trend was also observed among the households with landholdings of $0.5-2.0$ ha, which constitute $33 \%$ of the total households. On the other hand, households with less than 0.5 ha reported the highest proportion (65\%) of food self-insufficiency from their own produce. Nearly half of them (47\%) were food self-insufficient for more than 6 months and $25 \%$ were unable to fulfill their food needs for more than ten months from their own produce. Break down of this figure according to geographical region showed that $37 \%$ of the food self-insufficient households in tarai could not feed themselves for more than ten months from their own produce. This figure for hills and mountains is $17 \%$ and 9\%, respectively. World Food Program study indicates that the smallholders are more vulnerable to food security in Nepal (WFP 2001). It would mean that the households with lesser landholdings and prone to food selfinsufficiency are also more vulnerable to food security in Nepal.

Households that are food self-insufficient have been adopting different strategies to reduce, mitigate and cope with risks and shocks of food deficit. They can adjust to the shock of the food self-insufficiency in several ways: borrowing

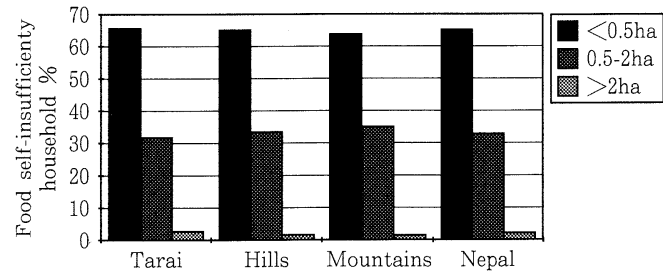

Fig. 5 Households according to landholding, food self-insufficiency and geographical region in Nepal

Source: CBS 2003a.

money and food, skilled and unskilled wage laboring, engaging in governmental and nongovernmental services, getting wage in kind, changing consumption patterns and rationing, feeding on cheaper and low quality grains, and going to forest for wild animals and edible plants and roots. However, the range of coping strategies available to households that are most vulnerable to food self-sufficiency are extremely limited by the availability of physical and human capital as well as social services. Manner of coping strategies may be different according to landholdings and the period of food selfsufficiency months. Households with shorter period of food self-insufficiency (1-3 months) can adjust with some change in eating habits, i.e., eating cheaper grains and rationing of the food. Most of the households with more landholdings often use this strategy during the lean periods of the year. But, this coping strategy alone is not sufficient to secure the household food needs for those who are food self-insufficient for more than four months. They have to pràctice combination of different coping strategies, such as borrowing, earning through various income generating activities and other petty ways. Fig. 6 indicates that large portion $(60 \%)$ of the households, more so in case of smallholders (64\%) depend on earnings from various income generating activities in the rural areas within the district. Many (20\%) of them also depend on seasonal and/or longterm migration, beyond the district, to supplement their traditional source of income to fulfill their household food needs. Some (11\%) even land up to foreign countries, especially India. 
Many (24\%) of the households with landholdings more than 2 ha also cope by borrowing as they generally have easier access to borrow money than the smallholders. Other coping strategies like changing consumption patterns, selling assets (land, livestock, jewelry, etc.), use of foods from jungle, have also been practiced by some (7\%) of the food self-insufficient households during various seasons of a year when the food stock dries out, i.e., during winter and pre-harvesting time. The manner of coping with the problem of food self-insufficiency by different households was surprisingly similar in all the geographical regions.

Although many of the households opt for earnings within the district to secure their household food needs, it may not necessarily guarantee their food security since such opportunities are rather limited due to stagnation of agriculture and weak economy, and the competition for such opportunities are made fierce by increase in population. In such a case most of the households with the longer food self-insufficient months, especially smallholders, may have to encounter it with combination of different strategies, including going to forests for wild animals and edible plants and roots, and often, doing away with the meals. Hence, this could simply mean the sharing of poverty and structural phenomenon of involution. However, further detail micro study with evidences at household levels would be needed to make this point clear.

\section{Conclusion}

Population growth is increasing pressure on man-land ratio, leading to expansion of agriculture in marginal land with lower yields, land fragmentation and increase in smallholders, all pertaining to decreasing per capita crop production. The incidence of poverty is high and is growing steadily both in rural and urban areas and worsening in terms of income distribution among the households, the income gap between the smallholders and large landholders being worst in tarai. The incidence of poverty is inversely related to landholdings of the households,

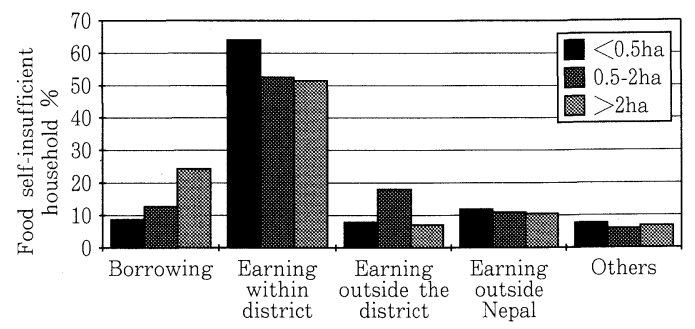

Fig. 6 Household's food self-insufficiency coping strategies according to landholding size in Nepal

Source: CBS 2003a.

i.e., smaller the size of landholding higher the incidence of poverty. Poverty indicates lower purchasing power and reduces the ability of households to access for food beyond their own produce, which makes them vulnerable to food security. On the other hand, land is the primary source of food and income for many of the Nepalese people. But, majority of them are smallholders with land less than 0.5ha per household and have many limitations to increase their production. They are basically food selfinsufficient and their numbers have been increasing in the recent decades.

The overall growth rate of food production in Nepal has not kept in pace with population growth rate. Nature dependent subsistence farming is risky and crop failure due to natural calamities may any time create transitory as well as chronic food insecurity, including famine. Hence, the manner of coping with food selfinsufficiency is important to manage food security at the household level. The food selfinsufficient households cope with risks and shocks of their food deficits by either or combination of the strategies, such as, borrowing money and food, skilled and unskilled wage laboring, engaging in governmental and nongovernmental services, petty trading, getting wage in kind, changing consumption patterns and rationing, feeding on cheaper and low quality grains, and going to forest for wild animals and edible plants and roots. Earning within the district by engaging in various income generating activities seems to be an important coping 
strategies for these food deficit households, especially the smallholders. However, due to the limit in such opportunities, primarily due to stagnating agriculture and weak economy, the smallholders who are prone to longer period of food self-insufficiency also have to encounter the problem with combination of different strategies, including consumption of jungle food and often, doing away with the meals.

Thus, the food self-sufficiency, directly related to landholding size, is an important indication of household food security in Nepal. The landholding size is again directly related to incidence of poverty and inversely related to amount of household income. The increase in smallholders recently could also be understood as the increase of the households that are food self-insufficient, poor and vulnerable to food security. This would necessitate more of the people to go to jungle for the food or do away with the meals, more often than before. This is a growing issue of food security needing an immediate attention of all concerned. For the agricultural country like Nepal, an increase in yield and production of own produces that could increase per capita food availability will be significant to increase the food self-sufficiency at the household level, which in turn would be effective in enhancing their food security and prevent them from falling into the vicious trap of poverty sharing and structural involution. Hence, emphasis should be given to sustainable increase in agriculture productivity with delivery of favorable physical inputs and technical know how, support in marketing and distribution systems, with efforts at various levels, including local government efforts, community efforts and farmers' efforts. Micro level study on such efforts of smallholders to improve their agriculture production and make themselves more food selfsufficient, hence be more food secure would be needed to understand this issue better. It will be dealt in the future researches of the authors.

\section{References}

[1] Adhikari, J. and H. G. Bohle 1997. Food
Crisis in Nepal. Delhi: Adroit Publishers.

[2] Agricultural Project Service Centre (APROSC) and John Mellor Association (JMA) 1995. Nepal Agriculture Perspective Plan. Kathmandu: His Majesty's Government of Nepal (HMG) and Asian Development Bank.

[3] Central Bureau of Statistics (CBS) 1993. National Sample Census of Agriculture. Kathmandu: HMG.

[4] CBS 2003a. National Sample Census of Agriculture, Nepal 2001/2002. Kathmandu: HMG.

[5] CBS 2003b. Population Monograph of Nepal (vol.1). Kathmandu: HMG.

[6] Food and Agriculture Organization (FAO) 1998. Nutrition Country Profile-Nepal. Rome: FAO.

[7] FAO 2004. Food Insecurity and Vulnerability in Nepal: Profiles of Seven Vulnerable Groups. Food Security and Agricultural Project Analysis Service (ESAF). ESAF Working Paper No.04-10, Rome: FAO.

[8] FAOSTAT 2004. www.fao.org. Statistics Database. Rome: FAO. (20/12/2004)

[9] Ministry of Agriculture and Cooperatives (MOAC) 2003. Statistical Information on Nepalese Agriculture. Kathmandu: HMG.

[10] Nepal South Asia Center (NESAC) 1998. Nepal Human Development Report 1998. Kathmandu: NESAC.

[11] Nepal Rastra Bank (NRB) 1988. Multipurpose Household Budget Survey. Kathmandu: NRB.

[12] Ojha, Ek Raj 1999. Dynamics and Development of Highland Ecosystems. Kathmandu: Walden Book House.

[13] Sharma, S. and D. Chhetry 1996. MIMAP Research on Poverty in Nepal: A Synthesis, Kathmandu: APROSC and International Development Research Centre.

[14] World Food Program (WFP) 2001. Food Insecurity and Vulnerability in Nepal: An Issue Paper. Kathmandu: VAM Unit, World Food Program Nepal. 